\title{
SARS-CoV-2 pandemia in Lombardy: the impact on family Paediatricians
}

\author{
Rinaldo Missaglia ${ }^{1}$, Michael Belingheri ${ }^{2}$, Laura Antolini ${ }^{2}$, Monica de' Angelis $^{3^{*}}$, Luca Brivio ${ }^{3}$, \\ Michele Augusto Riva ${ }^{2}$ and Simonetta Genovesi ${ }^{2,4}$
}

\begin{abstract}
As health care workers (HCWs) who care for children, who usually demonstrate milder symptoms than adults, family paediatricians have an increased risk of exposure to coronavirus. In April 2020, the Sindacato Medici Pediatri di Famiglia (SIMPeF), provided its members with rapid tests to detect antibodies against SARS-CoV-2; 1240 individuals, including 377 paediatricians, 108 staff members of pediatric clinics, and 755 cohabitant relatives of paediatricians, were tested in Lombardy, the most affected Italian region. The global prevalence of IgG antibodies in these individuals was $20.7 \%$, which is higher than that of the general population and other HCWs. More than $70 \%$ of subjects with IgG antibodies presented symptoms, and $4.9 \%$ needed hospitalization. In addition, $64.2 \%$ of the study participants reported close contacts with a suspected case of COVID-19, while $72.9 \%$ of the family paediatricians reported occupational exposure to the disease. The initiative of the SIMPeF has been useful in assessing the impact of the COVID-19 pandemic on paediatric settings, as well as in raising paediatricians' awareness of the spreading of coronavirus.
\end{abstract}

Keywords: Family paediatricians, Health care workers, COVID-19, SARS-CoV-2 antibodies

Novel coronavirus disease 2019 (COVID-19) outbreak has spread rapidly all over the world, having resulted in more than 42 million cases to date [1]. Health care workers (HCWs) have an increased risk of exposure to coronavirus, as do other individuals who work in health care settings, where they come into contact with patients $[2,3]$. Nevertheless, the risk of infection for HCWs who work in a COVID-19 designated department is debated. If on the one hand the use of proper personal protective equipment (PPE) and an increased awareness may reduce the risk of contagious, on the other an incorrect application and removal of PPE and particular clinical situations (such as practice location) may increase the risk $[4,5]$. Family paediatricians can be considered as a particular group of HCWs at even higher risk of

\footnotetext{
* Correspondence: monicadeangelis@fastwebnet.it

${ }^{3}$ Family Pediatrician, ATS Milan, SIMPeF Milan, Monica de'Angelis, Via Aosta 13, 20155 Milan, Italy

Full list of author information is available at the end of the article
}

contracting COVID-19 from their patients than other HCWs, due to the specific clinical features of coronavirus disease in children. Symptoms described in Italian and Chinese children are milder than those in the adult population. Furthermore, symptoms in children are usually not specific (as fever and/or cough), and many children with SARS-CoV-2 infection are asymptomatic, as can also happen in adults without comorbidities [6-8]. In the US, children with more severe symptoms (i.e. multisystem inflammatory syndrome in children associated with COVID-19 disease) have been described, but these are still relatively few cases $[9,10]$.

For these reasons, especially at the beginning of the outbreak, when no one knew the characteristics of this new disease, family paediatricians and their staff members may have therefore been exposed to coronavirus without adequate personal protective equipment.

The Sindacato Medici Pediatri di Famiglia (SIMPeF), provided its members who have accepted to be part of 
the study with rapid tests to detect IgG and IgM antibodies against SARS-CoV-2 to be administered to themselves, their collaborators and their cohabitant relatives. Therefore the study sample is made of three subsamples, one sample of paediatricians, one sample of staff members of paediatric clinics, one sample of paediatricians relatives. To account for the study design, and the subsequent non homogeneity, the statistical analysis was performed separately in the three subsamples. Out of 844. SIMPeF members (of which 824 resident in Lombardy, the most affected Italian region), 377 agreed to participate in the study. The presence of specific antibodies was tested in vitro using the 2019-nCoV IgG/IgM Rapid Test Cassette (ACRO BIOTECH, Inc.), a lateral flow chromatographic immunoassay for the qualitative detection of antibodies in human whole blood, serum, or plasma specimen. The technical manual reports the performance characteristics [11]. For the IgG results, relative sensitivity was $100 \%$ (95\% CI: $86.0-100)$, relative specificity was $98.0 \%$ (95\% CI: 89.4-99.9), and accuracy was $98.6 \%$ (95\% CI: 92.3-99.96), according to the manufacturer [11]. As to the IgM results, relative sensitivity was $85.0 \%$ (95\% CI: 62.1-96.8), relative specificity was 96.0\% (95\% CI: 86.3-99.5), and accuracy was 92.9\% (95\% CI: 84.1-97.6), as described in the technical manual [11].

Data was collected through an online questionnaire available on the SIMPeF website; the participants completed this questionnaire voluntarily and reported any symptoms related to COVID-19, any contacts with possible or confirmed COVID-19 cases, and rapid test results (IgG and $\operatorname{IgM}$ ). In some cases, especially when the rapid test was positive, a polymerase chain reaction (PCR) diagnostic test on nasal swabs was performed.

The study included 1240 individuals who lived in Lombardy, the most affected Italian region [12]. Specifically, 377 paediatricians, 108 staff members of paediatric clinics, and 755 cohabitant relatives of paediatricians were enrolled. To account for the study design, and the subsequent non homogeneity, the statistical analysis was conducted separately in the three subsamples. Table 1 presents the main characteristics of the study population. More women participated than men, and the average age of the participants was 48.3(17.0) years; the family paediatricians were older than the other subjects (Table 1).

All the participants were tested to detect IgG and IgM antibodies against SARS-CoV-2 in April 2020. However, this brief report addresses only the data on IgG antibodies. The global prevalence of IgG antibodies was $20.7 \%$ (257). Paediatricians and their staff members reported a similar prevalence of $14.9 \%$ (56) and $15.7 \%$ (17), respectively. A higher prevalence of $24.4 \%$ (184) was reported among the cohabitant relatives (Table 1). It is interesting to note that the prevalence of staff members with positive IgG was very similar to that of paediatricians. Moreover, cohabitant relatives of paediatricians reported a higher rate of IgG positive test than paediatricians themselves. These data suggest that doctors could have get infection not only from patients but also outside work.

Overall, 64.2\% (796) of the participants reported close contacts with a suspected case of COVID-19, even though only $32.4 \%$ (258) of those cases were confirmed to be coronavirus infection. Specifically, $62.6 \%$ (236) of the paediatricians were exposed to a suspected case, later confirmed in $77.5 \%$ (183) of these cases. Their staff members and cohabitant relatives described similar exposures to suspected COVID-19 patients; however, the diagnosis was confirmed in only $35.4 \%$ (23) and 37.5\% (182) of those cases, respectively. Occupational exposure was the main means of exposure for the paediatricians (72.9\%) and their staff members (69.2\%). Cohabitant relatives were exposed at the workplace in $44.0 \%$ of the cases, while $38.2 \%$ of these individuals reported having had close contact with a cohabitant relative affected by COVID-19.

Table 1 Main characteristics of study population $(N=1240)$

\begin{tabular}{|c|c|c|c|c|c|c|c|c|}
\hline \multirow[t]{2}{*}{ Variables } & \multicolumn{2}{|l|}{ Total } & \multicolumn{2}{|c|}{ Paediatricians } & \multicolumn{2}{|c|}{ Staff members } & \multicolumn{2}{|c|}{ Cohabitant relatives } \\
\hline & $\bar{N}$ & $\%$ & $\bar{N}$ & $\%$ & $\bar{N}$ & $\%$ & $\bar{N}$ & $\%$ \\
\hline Age [average (DS)] & \multicolumn{2}{|l|}{$48.3(17.0)$} & \multicolumn{2}{|l|}{$57.2(7.2)$} & \multicolumn{2}{|l|}{$48.4(10.1)$} & \multicolumn{2}{|l|}{$43.8(19.3)$} \\
\hline \multicolumn{9}{|l|}{ Gender } \\
\hline Male & 495 & $39.9 \%$ & 88 & $23.3 \%$ & 3 & $2.8 \%$ & 404 & $53.5 \%$ \\
\hline Female & 745 & $60.1 \%$ & 289 & $76.7 \%$ & 105 & $97.2 \%$ & 351 & $46.5 \%$ \\
\hline \multicolumn{9}{|l|}{ Rapid test } \\
\hline IgG positive & 257 & $20.7 \%$ & 56 & $14.9 \%$ & 17 & $15.7 \%$ & 184 & $24.4 \%$ \\
\hline IgG negative & 983 & $79.3 \%$ & 321 & $85.1 \%$ & 91 & $84.3 \%$ & 571 & $75.6 \%$ \\
\hline \multicolumn{9}{|c|}{ Symptoms among lgG + } \\
\hline At least one & 192 & $74.7 \%$ & 44 & $78.6 \%$ & 12 & $70.6 \%$ & 136 & $73.9 \%$ \\
\hline No symptoms & 65 & $25.3 \%$ & 12 & $21.4 \%$ & 5 & $29.4 \%$ & 48 & $26.1 \%$ \\
\hline
\end{tabular}


As to the serological test results, a total of 185 out of 257 IgG positive study participants were exposed to close contact with a suspected case of Covid-19. The gap time in days between time of contact and test administration had an average of 45 days and a standard deviation of 13 days ( $\mathrm{q} 1=39$ days, $\mathrm{q} 3=52$ days).

Overall, almost three in 10 participants had symptoms related to COVID-19 in the weeks before the tests. Interestingly, $79.8 \%$ (292) of the symptomatic participants had had previous close contact with a suspected COVID-19 case, while only $57.6 \%$ (504) of asymptomatic participants had had it.

More than $70 \%$ of study participants who tested positive related having demonstrated symptoms compatible with SARS-CoV-2 infection. Specifically, $78.6 \%$ of the paediatricians, $70.6 \%$ of the staff members, and $73.9 \%$ of the cohabitant relatives with a positive serological test reported symptoms (Table 1). The date of symptoms occurrence was available for 151 out of 192 IgG positive study participants who had symptoms. The gap time in days between time of contact with a suspected case of Covid-19 and symptoms onset had an average of 6.8 days and a standard deviation of 13.2 days $(\mathrm{q} 1=6$ days, $\mathrm{q} 3=$ 10 days).

The most common symptoms were fever (100\%), anosmia (57.2\%), ageusia (54.1\%), gastrointestinal disorders (53.3\%), shortness of breath (24.1\%), and oxygen saturation $<95 \%(16.3 \%)$. Among the symptomatic participants, $4.9 \%$ (18) needed hospitalization due to the severity of their clinical conditions.

Polymerase chain reaction diagnostic tests on nasal swabs were performed in $26.6 \%$ (71) of the positive serology tests and $8.3 \%(82)$ of the negative serology tests. It was thus possible to estimate the performance characteristics of the used serological test. We found a relative sensibility of $96.0 \%$ and a relative specificity of $79.2 \%$.

The Italian National Institute of Statistics (ISTAT) recently published a report on the seroprevalence of antibodies against SARS-CoV-2 in the Italian population [13]. According to ISTAT, about $2.5 \%$ of Italians have antibodies for the novel coronavirus, with a significant difference between regions. Indeed, about $50 \%$ of individuals with antibodies live in Lombardy, where the seroprevalence is around $7.5 \%$, which is up to seven times higher than in other regions, where there was the lowest level of virus spreading. Concerning HCWs, ISTA $\mathrm{T}$ reported that their seroprevalence is higher than that of the general population, reaching almost $10 \%$ in those regions that the pandemic has affected most.

Although these data were collected differently than those collected for this study, the ISTAT report is interesting and useful for interpreting the current results. This research indicates that about $15 \%$ of the paediatricians and staff members of paediatric clinics had IgG antibodies for SARS-CoV-2, which is higher than the percentages for the general population of Lombardy and other HCWs. This finding may suggest that paediatricians and their staff members have been highly exposed to the novel coronavirus, especially at the beginning of the pandemic, when knowledge of the virus was limited. Moreover, paediatricians' relatives also had a higher seroprevalence than the general population. Hence, in this recent new peak of pandemic, it is important that paediatricians use correctly PPE and separate patients with covid-19 related symptoms from other patients, scheduling different appointments, as also suggested by the Italian Pediatric Society [14].

Finally, the current results confirm that the rapid tests used in this screening have a decent performance in terms of sensibility, while specificity stopped at $80 \%$. However, the initiative of SIMPeF has been extremely useful in assessing the impact of the COVID-19 pandemic on paediatric settings and to raise awareness family paediatricians about the spreading of coronavirus, at a time when the world was faced with few certainties and many unknowns.

\section{Abbreviations}

COVID-19: Corona virus disease 2019; HCWs: Health care workers; IgG: Immunoglobulin G; IgM: Immunoglobulin M; ISTAT: Istituto nazionale di statistica (Italian national institute of statistics); PCR: Polymerase chain reaction; PPE: Personal protective equipment; SARS-CoV-2: Severe acute respiratory syndrome - coronavirus - 2; SIMPeF: Sindacato medici pediatri di famiglia

\section{Acknowledgments}

We thank all the SIMPeF paediatricians who made it possible to carry out the study.

\section{Authors' contributions}

SG conceptualized and designed the study, drafted the initial manuscript, and reviewed and revised the final manuscript; RM, MdA and LB collected data and gave organizational support to the study; LA performed data analysis, MdA, MB and MR drafted, reviewed and revised the final manuscript. All authors approved the final version of the manuscript.

\section{Authors' information}

SG is associate professor of Nephrology at the University of Milan Bicocca and director of the Center for Cardiovascular Prevention in the Pediatric Age of the IRCCS Auxologico of Milan; LA is associate professor of Statistics at the University of Milan-Bicocca; RM, MdA and LB are Family Pediatricians, members of the Union of Family Pediatricians (SIMPef); MB and MR are researchers from Milan-Bicocca and work at the Institute of Occupational Medicine of the S. Gerardo Hospital in Monza.

\section{Funding}

No funding were used to carry out the study.

\section{Availability of data and materials}

The data were collected on the portal www.simpef.it and are in possession of the SIMPeF. The datasets used and/or analysed during the current study are available from the corresponding author on reasonable request.

\section{Ethics approval and consent to participate}

All paediatricians who have anonymously provided the data signed an informed consent form and had their collaborators and cohabitants sign it. In the case of minors, parental consent has been obtained. 


\section{Consent for publication}

Not applicable.

\section{Competing interests}

None of the authors declares a conflict of interest.

\section{Author details}

${ }^{1}$ Family Pediatrician, ATS Brianza, SIMPeF Milan, Milan, Italy. ${ }^{2}$ School of Medicine and Surgery, University of Milano-Bicocca, Monza, Italy. ${ }^{3}$ Family Pediatrician, ATS Milan, SIMPeF Milan, Monica de'Angelis, Via Aosta 13, 20155

Milan, Italy. ${ }^{4}$ Cardiologic Unit, Istituto Auxologico Italiano, IRCCS, Milan, Italy.

Received: 21 September 2020 Accepted: 14 December 2020

Published online: 21 December 2020

\section{References}

1. World Health Organization. COVID-19 Weekly Epidemiological Update - 27 October 2020 [Internet]. 2020. Available from: https://www.who.int/ publications/m/item/weekly-epidemiological-update\%2D\%2D-27-october-2 020.

2. Belingheri M, Paladino ME, Riva MA. COVID-19: Health prevention and control in non-healthcare settings. Occup Med. 2020;70(2):82-3.

3. Belingheri M, Paladino ME, Riva MA. Beyond the assistance: additional exposure situations to COVID-19 for healthcare workers. J Hosp Infect. 2020; 105(2):353.

4. Boffetta P, Violante F, Durando P. De Palma G, Pira E, Vimercati L, et al. Determinants of SARS-CoV-2 infection in Italian healthcare workers: a 264multicenter study. medRxiv. 2020. https://doi.org/10.1101/2020.07.29. 20158717.

5. Nguyen LH, Drew DA, Graham MS, Joshi AD, Guo C-G, Ma W, et al. Risk of COVID-19 among front-line health-care workers and the general community: a prospective cohort study. Lancet Public Heal. 2020;5(9):e47583.

6. Qiu H, Wu J, Hong L, Luo Y, Song Q, Chen D. Clinical and epidemiological features of 36 children with coronavirus disease 2019 (COVID-19) in Zhejiang, China: an observational cohort study. Lancet Infect Dis. 2020;20(6): 689-96.

7. Lu X, Zhang L, Du H, Zhang J, Li YY, Qu J, et al. SARS-CoV-2 infection in children. N Engl J Med. 2020;382(17):1663-5.

8. Parri N, Lenge M, Buonsenso D. Children with Covid-19 in Pediatric Emergency Departments in Italy. N Engl J Med. 2020;383(2):187-90.

9. Dufort EM, Koumans EH, Chow EJ, Rosenthal EM, Muse A, Rowlands J, et al. Multisystem inflammatory syndrome in children in New York state. N Engl J Med. 2020;383(4):347-58.

10. Feldstein LR, Rose EB, Horwitz SM, Collins JP, Newhams MM, Son MB, et al. Multisystem Inflammatory Syndrome in US Children and Adolescents [published online ahead of print June 29, 2020]. N Engl J Med. 2020;383(4): 334-6. https://doi.org/10.1056/NEJMoa2021680.

11. ACRO BIOTECH Inc. 2019-nCoV IgG/lgM Rapid Test Cassette - ACRO BIOTECH, INC (Technical Manual) [Internet]. 2020. Available from: https:// www.assaygenie.com/content/AcroBiotech/ACROPacklnsert.pdf.

12. Belingheri M, Paladino ME, Piacenti S, Riva MA. Effects of COVID-19 lockdown on epidemic diseases of childhood. J Med Virol. 2020

13. Istituto Nazionale di Statistica (ISTAT). Primi risultati dell'indagine di sieroprevalenza sul SARS-CoV-2 [Internet]. 2020. Available from:https://www. istat.it/it/files//2020/08/ReportPrimiRisultatilndagineSiero.pdf.

14. Agostiniani R, Bozzola E, Staiano A, Del Vecchio A, Mazzone T, Greco L, et al. Providing pediatric well-care and sick visits in the COVID-19 pandemic era: the recommendations of the Italian pediatric society. Ital J Pediatr. 2020; 46(1):1-4.

\section{Publisher's Note}

Springer Nature remains neutral with regard to jurisdictional claims in published maps and institutional affiliations.

Ready to submit your research? Choose BMC and benefit from:

- fast, convenient online submission

- thorough peer review by experienced researchers in your field

- rapid publication on acceptance

- support for research data, including large and complex data types

- gold Open Access which fosters wider collaboration and increased citations

- maximum visibility for your research: over $100 \mathrm{M}$ website views per year

At BMC, research is always in progress.

Learn more biomedcentral.com/submissions 